January 2015

\title{
Merging Special Collections with GIS Technology to Enhance the User Experience
}

Gina L. Nichols

San Jose State University, gln6816@gmail.com

Follow this and additional works at: https://scholarworks.sjsu.edu/ischoolsrj

Part of the Archival Science Commons, and the Collection Development and Management Commons

\section{Recommended Citation}

Nichols, G. L. (2016). Merging Special Collections with GIS Technology to Enhance the User Experience. School of Information Student Research Journal, 5(2). https://doi.org/10.31979/2575-2499.050205 Retrieved from https://scholarworks.sjsu.edu/ischoolsrj/vol5/iss2/5

This article is brought to you by the open access Journals at SJSU ScholarWorks. It has been accepted for inclusion in School of Information Student Research Journal by an authorized administrator of SJSU ScholarWorks. For more information, please contact scholarworks@sjsu.edu. 


\title{
Merging Special Collections with GIS Technology to Enhance the User Experience
}

\begin{abstract}
This analysis evaluates how PhillyHistory.org merged their unique special collection materials with geospatial-based progressive technology to challenge and educate the global community. A new generation of technologically savvy researchers has emerged that expect a more enhanced user experience than earlier generations. To meet these needs, collection managers are collaborating with community and local institutions to increase online access to materials; mixing best metadata practices with custom elements to create map mashups; and merging progressive GIS technology and geospatial based applications with their collections to enhance the user experience. The PhillyHistory.org website was analyzed to explore how they used various geospatial technology to create a new type of digital content management system based on geographical information and make their collections accessible via online software and mobile applications.
\end{abstract}

\section{Keywords}

crowdsourcing, geospatial, GIS technology, Google Earth, Google Maps, PhillyHistory.org, special collections, user experience

\section{About Author}

Gina Nichols is the archivist for the U.S. Navy Seabee Museum at Naval Base Ventura County, Port Hueneme, CA. Nichols has master's and baccalaureate degrees in history from California State University Northridge with concentrations in U.S. history and archival management. She is currently working on her MLIS at San Jose State University focusing on information science and digital curation. 


\section{Introduction}

For archivists, librarians and curators, a plethora of new digital technologies are available that, when combined with their special collections, ${ }^{1}$ can create a more enhanced participatory user experience and shed new light on their depth and breadth. Integrating technology and mobile applications with their collections attracts new audiences to their institutions and creates a unique user experience for their patrons who have a broader range of needs and expectations.

Twenty-first century collection managers have reached a point where they must provide more innovative digital services to patrons or risk becoming irrelevant. One of the ways institutions are transforming their collections is by merging geospatial technology with historic materials to transform how the public views and interacts with them. The latest generation of researchers now identify with technology and are more open to innovative experiences. They require, and often demand, a more enhanced technological experience than earlier generations of researchers. Institutions must constantly adapt to attract and challenge this new style of researcher or risk becoming obsolete as other institutions integrate technology with their collections. The problem collection managers must now contend with is how to influence and appeal to this new breed of researcher while continually merging collections with cutting edge technology.

One institution that has merged and adapted their unique collection with GIS technology and crowdsourcing is PhillyHistory.org, developed by the City of Philadelphia Department of Records. This paper will analyze how PhillyHistory.org collaborated with community and local institutions; mixed best metadata practices with custom elements to create map mashups; and merged progressive GIS technology and geospatial-based applications with their collections to enhance the user experience.

\section{Background}

\section{Geographic Information System (GIS)}

Geographic Information System, or GIS, is a computer-based tool to assist in mapping and analyzing "things that exist and events that happen on earth" (Geo Community, 2015). GIS integrates common database operations and statistical analysis with visualization and geographical analysis of other maps.

GIS enables institutions to create maps, integrate information, visualize locations, present collections in a new innovative way, and develop unique solutions to enhance user's access and website interaction (Geo Community,

\footnotetext{
${ }^{1}$ For the purposes of this paper special collections or collections will refer to any type of archival, manuscript, museum, digital, or public history collection.
} 
2015). This technology takes map making and geographic analysis to a new level by advancing the field and making it faster than old methods.

\section{Google Maps}

In 2005, Google launched its new online map service Google Maps. Now, 10 years later, the features in Google Maps and other online map services have become indispensable to users. Google Maps permits users to view maps, get directions between two locations, see topographical terrain, and view satellite imagery. Recently added was a traffic alert feature to allow users to avoid accidents and evade slow transportation flows (Strickland, n.d.).

Google Maps relies on digital map images provided by NAVTEQ to enhance their technology. Google merged NAVTEQ applications with Atlas, their own in-house mapping program, to create the features you now see on Google Maps (Miller, 2014). Other features include walking directions and Street View, a massive operation that requires extensive amounts of human labor to acquire all the data, humans to compile the data, and operators to massage the data and enhance the view. These operators go through thousands of images and add data including small changes to make the roads easier see, parking lots standout, and walking paths viewable (Madrigal, 2014).

\section{Google Earth}

Google Earth is a geobrowser that uses satellite and aerial imagery, ocean bathymetry, and a host of geographic data accessible over the internet to create 3D global representations of the Earth (Science Education Resource Center, 2015). As one zooms in you are going through a series of successive images to get closer shots that range from a NASA satellite to an aerial image depending on the location. A geobrowser is a virtual globe that allows browsing of the Earth or other planetary entity (Science Education Resource Center, 2015). NASA often creates and uses geobrowsers in their virtual exhibits and 3D visualization displays.

Google Earth provides search capabilities plus the ability to pan, zoom, rotate, and tilt the Earth. New features allow the creation of layers that can include maps, photographs, geographic terrain and data like volcanoes, populations, and public works information like sewers or historic maps (Science Education Resource Center, 2015). This capability, merged with historic collections, can create a new and unique experience for our researchers. 


\section{Literature Review}

\section{Collaboration}

Special collection managers are broaching the issue of how to take their materials from static collections to the digital realm while simultaneously engaging their communities. With limited resources and shrinking staffs, many are turning to collaborative partnerships with other institutions, volunteer organizations, academia, and the local community to develop broader, richer online sites.

In response to Meissner and Greene's article More Product, Less Process, ${ }^{2}$ OCLC has argued that libraries and other information institutions should increase digitization efforts focusing more on quantity rather than quality to increase access to hidden or inaccessible collections (Erway and Schaffner, 2007, p. 3). This has encouraged the mass digitization of all special collection materials, which many have begun, before they have the infrastructure in place to maintain or the funding established to migrate digital materials in perpetuity.

Some of the main issues institutions confront are inconsistent funding and lack of internal support. Information institutions that engage in digitization and succeed seemingly rely on cross-departmental group projects to leverage staff expertise (Gueguen and Hanlon, 2009, p. 3). Smaller institutions, often hosted by one larger institution, are banding together to form consortium style projects, combining funding, equipment, staff, and subject matter expertise to create cost effective multi-dimensional digital collections that they would never otherwise be able to produce.

The San Fernando Valley History Digital Library (2015) at California State University Northridge (CSUN) brought together significant historical photographs, illustrations, maps, manuscripts, and various archival materials from a variety of collections located on the CSUN campus, as well as archival material from twenty-nine local historical societies in the San Fernando Valley. The digital library was one of the first to collaborate campus collections with local historical collections assisting smaller institutions to increase access and providing one online resource for San Fernando Valley history (San Fernando Valley History, 2015).

CENDARI (2015) is another successful example of a collaborative digital archive that merges archival, manuscript, and library materials across both institutional and national borders at one easily accessible location for scholars. The project is funded by the European Union and fourteen major research

\footnotetext{
${ }^{2}$ More Product, Less Process, written by Dennis Meissner and Mark Greene and published in the American Archivist in Fall/Winter 2005 issue, is an influential article advocating minimal processing of archival collections to reduce backlogs and increase access to long hidden and inaccessible archival collections.
} 
institutions providing a major educational resource on a global platform (CENDARI, 2015). These initiatives represent some of the most viable approaches for institutions to adapt to the ever-evolving workplace dynamic that includes increased requirements and shrinking budget and staff (Hunter, et al., 2010, 85).

The University of Maryland established new policies to coordinate and plan digital initiatives and to develop a central digital repository to house all digitized collections. The institution's goal aimed to limit re-scanning of frequently requested materials and repurpose materials that had already been scanned. All future materials scanned for historical or patron requests would be added to the digital repository. This would serve two purposes - to assist patrons with requests while simultaneously increasing global access to archival and manuscript collections (Gueguen and Hanlon, 2009, p. 1). In order to maximize labor dollars and minimize rework or damage to the collection, many institutions are redefining and restructuring their digital workflows utilizing similar strategies.

Utilizing volunteers and interns in archival digitization projects is another way institutions can collaborate with local patrons, groups, and colleges to engage the communities they serve. Including volunteers and interns in projects allows institutions to promote user involvement, increase metrics, add value to the work, and allow staff to increase their work production in areas they would otherwise not be able to complete (Howlett, et al., 2005, pp. 12-13). Both are invaluable resources allowing the institution to increase public programs, online resources, and educate the community.

\section{Map Mashups}

Mashups are interactive web applications that use content from several sources to create a single display showing all the graphical sources (Engard, 2012, p. 3). The simplest type of map mashup can be created by simply adding a map link to your site indicating the institution's location. Other mashups mix photographs, videos, social media, and news feeds most of which can be done in-house with moderate technological expertise. This new type of application allows institutions to merge collections with maps and GIS type software to challenge and entertain patrons.

One term that has emerged in special collection's jargon is the notion of "shareable" metadata (Riley and Shepard, 2009, p. 91). Patrons' expectations have risen demanding institutions increase collection access whether through finding guides, digital content, or interactive applications. One way collection managers are sharing their collections and descriptive metadata is by combining materials, especially those with a geographic component, such as architectural records and general development maps, and integrating GIS services such as Story Maps, Google Maps, and Google Earth (Riley and Shepard, 2009, p. 94). 
There are many different map applications that can be used to create an enhanced user experience between the collections and community. One is Story Maps which allows individuals and communities to create and share information in a 3D atmosphere (Engard, 2014, p. 33). The software allows you to combine authoritative maps with narrative text, images, and multimedia content (Story Maps, 2015). Story Maps enables institutions to connect with their audience by crafting text, maps, and digital materials to engage them. Another possibility is to create walking or driving tours of your institutions, community highlights, or local historic events. The software is fully customizable to allow the institution to mix historic materials, photographs, and text in layers to create an enhanced, engaging site for the global and mobile communities.

The Bassi-Veratti Collection is a multi-year collaboration between the Stanford University Libraries, the Biblioteca Comunale dell'Archiginnasio, Bologna, Italy, and the Istituto per i Beni Artistici, Culturali e Naturali della Regione Emilia-Romagna, to create a digital archive of Laura Bassi, an influential female scientist. The collection contains archival materials related to Bassi; her husband, scientist Giuseppe Veratti; and their family (Stanford, n.d.). The BassiVeratti archive took advantage of geospatial mashup components that allow sites to merge archival materials, text, and Google Maps to assist researchers (Engard, 2014 , p. 255). The interactive map allows the user to geographically explore content by location as well as document type; personal, corporate, or family name; and date.

The Nagasaki Archive (2015) designed a unique approach to teach the lessons of Atomic War and its aftermath through survivor oral histories, archival materials, and geospatial imagery using Google Earth, topographic data, and historic maps. The digital archive allows the user to view images on the Google Earth globe at the same angle they were taken 70 years ago allowing better visual understanding of the events and aftermath. Survivor stories, shown on the map, allow users to see exactly where they were exposed to the Atomic bomb and read their personal experiences. Displays also include current photographs that allow users to visualize reconstruction over time (Nagasaki Archive, 2015). Nagasaki Archive merges resources from all over the world in an attempt to reorganize the information using a digital virtual globe, allowing users to visualize the survivor's experiences and experience what Nagasaki endured and how it reemerged. This unique use of Google Earth and geospatial data, merged with archival materials and oral histories, creates an interactive experience that engages, challenges, and educates patrons.

\section{User Experience}


While most information institutions are not in the for-profit business, they do have a responsibility to deepen the connection between their institution and their patrons whether onsite or in the digital realm. Enhancing the User Experience (UX) means to deepen their feelings when they use the site or visit the facility (Schmidt and Etches, 2014, p. 1). This has become an integral part of special collection institutions compelling them to learn how to engage, attract, and inspire their patrons in the digital realm.

One of the more popular ways institutions are inspiring patrons to engage with and enhance online collections is through personal contributions. Patrons help develop new exhibits and online sites by providing feedback during visits; adding tags, opinions, and comments on storyboards and content pages; and attaching memories, documents, and photographs in online reflective spaces. Allowing online and onsite visitors to add content "personalizes and diversifies the voices" (Simon, 2010, p. 203) at institutions, enhancing the complexity and scope of the original exhibit or digital project. The original product takes on a life of its own, growing and branching off in unforeseen ways to become a much more poignant piece.

The New York Public Library is updating its Rare Books Division by reaching out to patrons and the community for volunteers to assist them in digitizing and adding metadata to more than 40,000 menus collected since 1900 . In addition, the volunteers are creating a fully searchable database for scholars and anyone interested in historically-themed restaurant information (Day, 2011). This project invites the community to take an active part in the preservation of local history, engaging them not only with the institution but in the effort to increase access to historic New York culture and events.

A new and growing trend of crowdsourcing in special collections is patron transcription of handwritten papers, diaries, logs, and rare books. Volunteers are donating their time to transcribe tens of thousands of digitized pages for archives, libraries, and other public history institutions (Day, 2011). The Old Weather site focuses on volunteers transcribing hundreds of thousands of ship's logs to assist scientists in improving knowledge of past environmental conditions and contribute to climate model projections (Bentham, 2011). Historians use the volunteer's work to track past ship movements and convey the stories of the people on board (Old Weather, 2015).

The University of Iowa Libraries launched an exhibition and digital collection to commemorate the Civil War sesquicentennial in 2011. The exhibit and digital collection contain thousands of diary pages from three manuscript collections held by Special Collections and University Archives which offer a unique perspective on the war. As part of the digital collection project, volunteers painstakingly reviewed over 3,000 digitized pages and transcribed the handwriting of hundreds of different writers and checked each other for accuracy 
(Wolfe, 2011). This unique, hands-on effort allows participants to view and experience a more personal side of American history. This new type of crowdsourcing is revolutionizing the digital humanities by creating an inclusive experience for the public and scholars who can now not only access the materials but also create a personal experience with the people and events from a significant period in our nation's history.

\section{Methodology}

One institution that merged their historic collections with GIS technology, Google Maps and Google Earth to enhance their collections and the user experience is PhillyHistory.org. With its unique subject matter, records, and community, PhillyHistory.org approached the issue of online access and metadata element choice by linking the collection with geospatial-based applications and metadata. The institution uses Dublin Core elements and custom advanced options with crowdsourcing techniques to engage patrons and enhance the collection.

The analysis of PhillyHistory.org will identify collaborative methods used to develop more comprehensive, rich collections; what metadata elements and advanced options were selected; and how they initially approached and continue to expand their project using geospatial technology to enhance the user experience.

\section{Case Study: PhillyHistory.org}

The City Archives, part of the City of Philadelphia Department of Records (DOR), manages the official historical records for the City of Philadelphia. Part of this collection is a large historic photograph collection taken by public works, city planners, and other city offices that visually documents the history of Philadelphia (Boyer, Cheetham and Johnson, 2011, p. 652). The photographs include images of buildings, streetscapes, parks and waterways dating back to 1865 . These stunning pictures show horse-drawn carriages on cobblestone streets, historic homes and buildings, wooden hulled ships arriving at the port, and the city's most historic buildings and sites including Independence Hall, Eastern State Penitentiary, and the Liberty Bell (ERSI, 2005, p. 1).

DOR houses an estimated one to two million images taken as part of public works projects to provide process documentation and serve as a risk management tool. Unbeknownst, these images, taken by city workers in the course of their daily work, also served to make Philadelphia one of the best historically photographed cities in America. These images provide a visual interpretation of

the past and the ability for the public to see one of America's most historically significant cities transform over the course of the last 150 years (Boyer, et al., 2011, p. 652). 


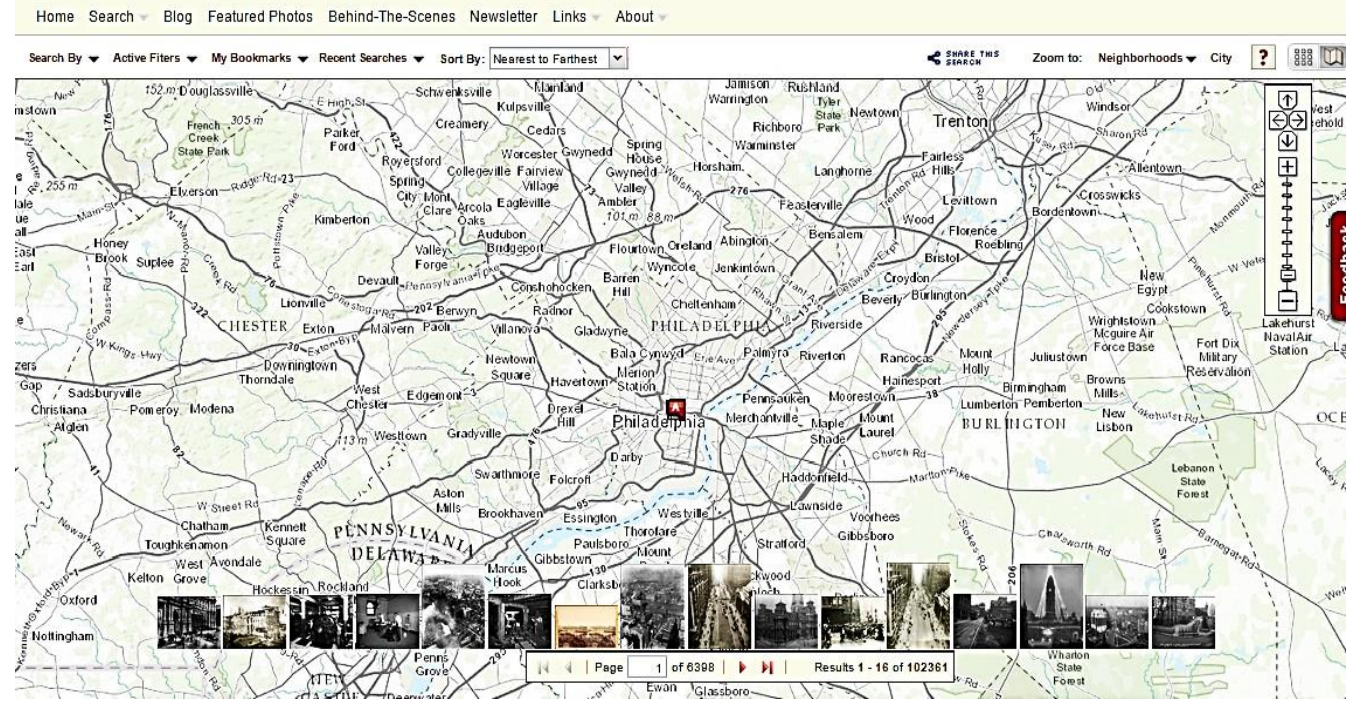

Figure 1: Map search view on PhillyHistory.org.

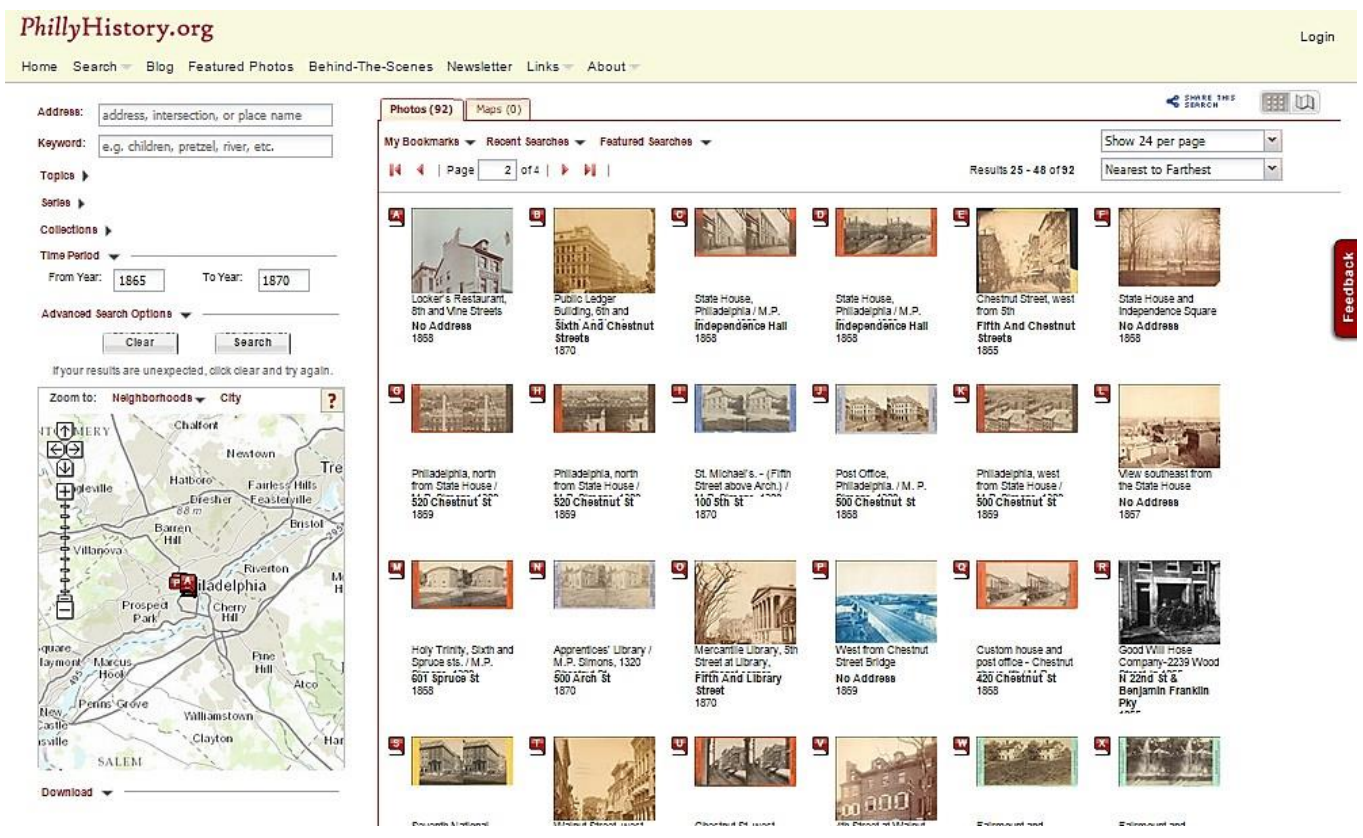

Figure 2: The PhillyHistory.org thumbnail-base search page showing search options, geographic information, and thumbnail views of search results. 
DOR, however, recognized these images had minimal value stored in the stacks, inaccessible and unseen by most of the public. Creating an online digital archive solved several issues facing DOR including preservation, increasing public and civilian worker access, gaining intellectual and physical control of the collection, and enhancing the user experience.

In 2004, in an effort to provide increased access to the photographic collection, DOR began searching for programs and companies that could make their images available in digital format. Besides requiring a site to increase access to each image, they wanted a system to provide a way to manage the various geographic and metadata information associated with each photograph to ease location of streets, neighborhoods, and businesses. Another requirement for the site was a revenue-generating component to support the project and expand the digitization capability (Boyer, et al., 2011, p. 653).

DOR, working in consultation with Azavea, a software company specializing in GIS, launched PhillyHistory.org in 2005 (City of Philadelphia, 2011, p. 5). The new web-based digital asset management system brought Philadelphia's images out of the stacks and into the $21^{\text {st }}$-century utilizing web-based GIS applications. This allows the public to search for locations within a specific radius of an address, near an intersection, or by a place-name (ERSI, 2005, p. 1)

A major aspect added to this site is the use of geographic information system (GIS) technology. Each image is geocoded, which assigns latitude and longitude coordinates linking it to a mapping feature on PhillyHistory.org, enabling users to search the site by street address, intersection, neighborhood name or to view the location of each image on a map or satellite viewpoint (Boyer, et al., 2011, p. 654). This is one of the most beneficial and unique features of the website allowing patrons to search the geographic information as well as by collection or business name.

In an effort to streamline search access to tens of thousands of images covering the sprawling streets of Philadelphia, PhillyHistory.org includes several visual search pages, Map View (see Figure 1) and Thumbnail View (see Figure 2), that enable users to visually search photographs by geographic location (address, intersection, business or place name, and neighborhood), keyword, topic, series, collection, time period, and advanced search options. Map View, utilizing Google Maps open-source software, allows the user to narrow down their images by zooming into a specific location and view the images at the bottom of the screen.

In Thumbnail View, each image is visible in a thumbnail with a title or basic location details with a Google Map on the left side to assist the patron with geographical orientation. When the user clicks on the thumbnail image, a larger detailed view of the image appears showing metadata fields, a small map indicating the photograph location, and the ability to view the location in Google 


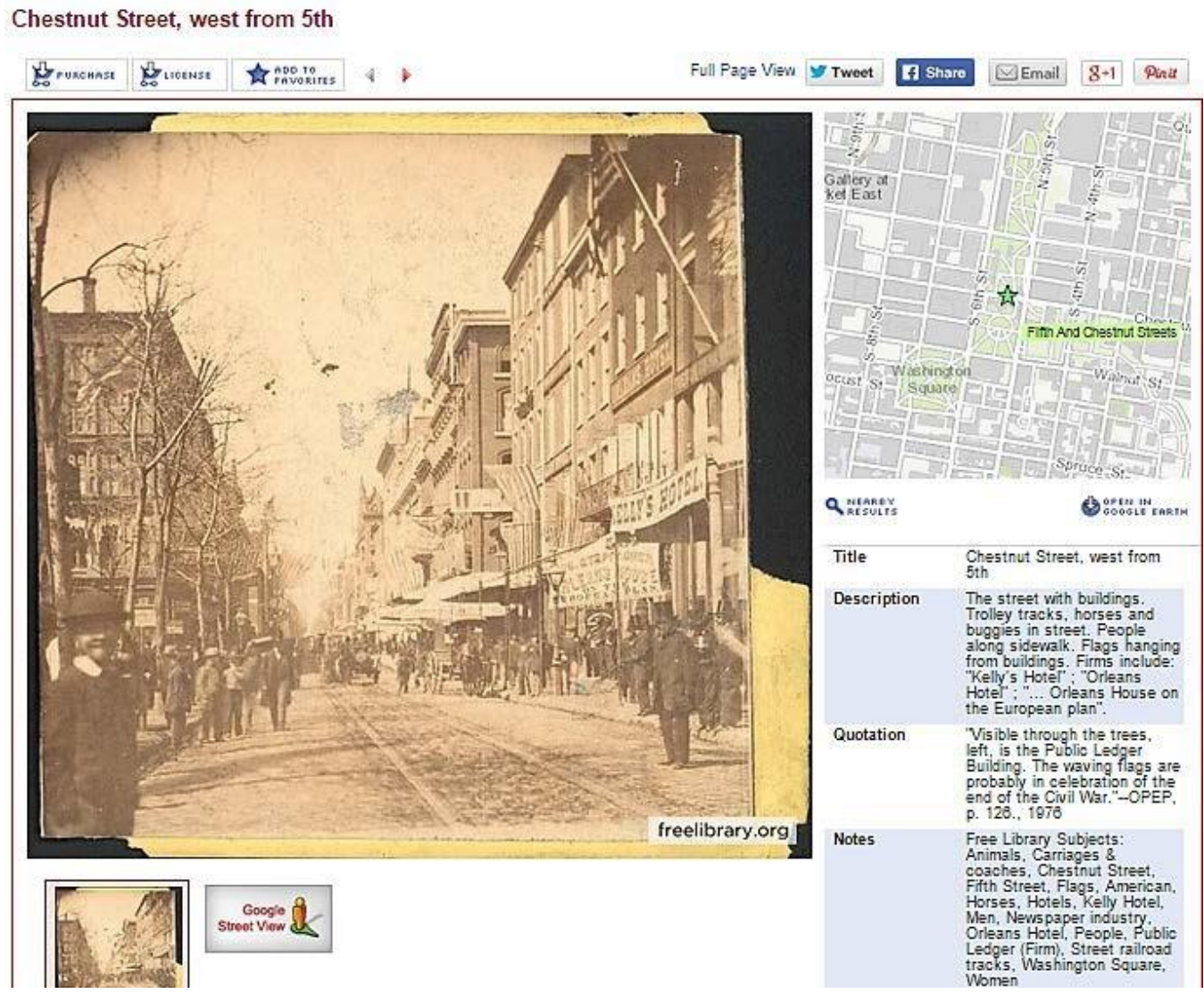

Figure 3: PhillyHistory.org detailed view showing Chestnut Street, west from $5^{\text {th }}$ photograph.

Earth or Google Street View to see how it looks today (see Figure 3). The larger detailed version allows users to save the image at a sufficiently high enough resolution to be used by students, city workers, or researchers without requiring purchase. Another popular feature is the Philadelphia Historic Street Index that matches former street names to their current names, making it easier for researchers or historians to find current addresses of historic buildings or residences.

In an effort to keep their project on the cutting-edge of technology and innovation, PhillyHistory.org added Google Earth to their list of features in October 2007. The site offers three different ways to display Google Earth. The first provides a button saying "Show in Google Earth" on all images with location capability allowing the displayed image to be viewed. The second allows the first 100 records of any search to be shown as a group on the Google Earth aerial view (see Figure 4). Finally, the site offers a feature allowing patrons to view the entire 


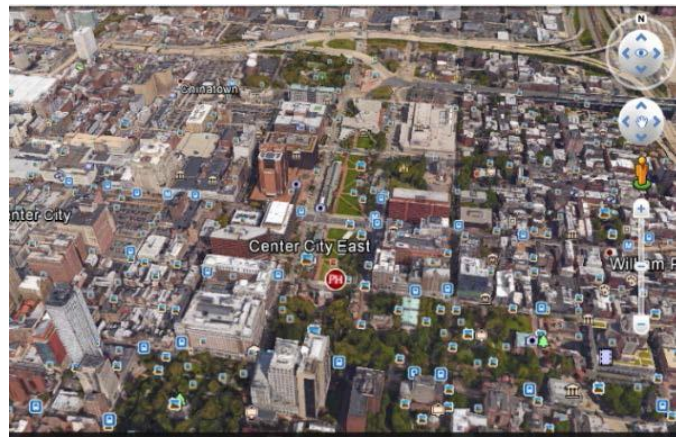

Figure 4: Google Earth aerial view of downtown Philadelphia.

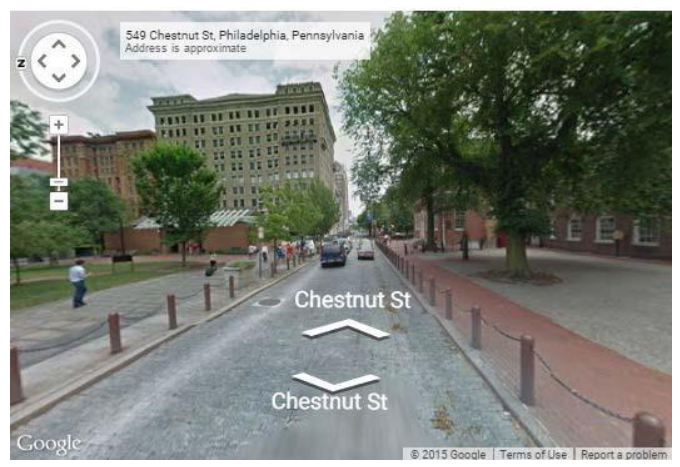

\section{Figure 6: Google Street View of Chestnut Street west of $5^{\text {th }}$.}

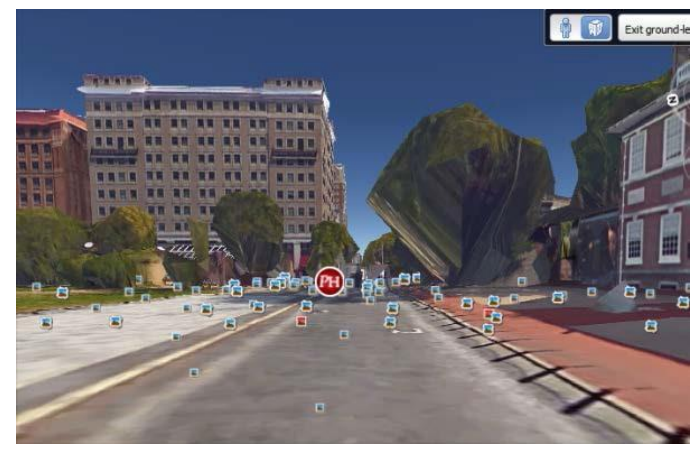

Figure 5: Google Earth street view of Chestnut street west of $5^{\text {th }}$.

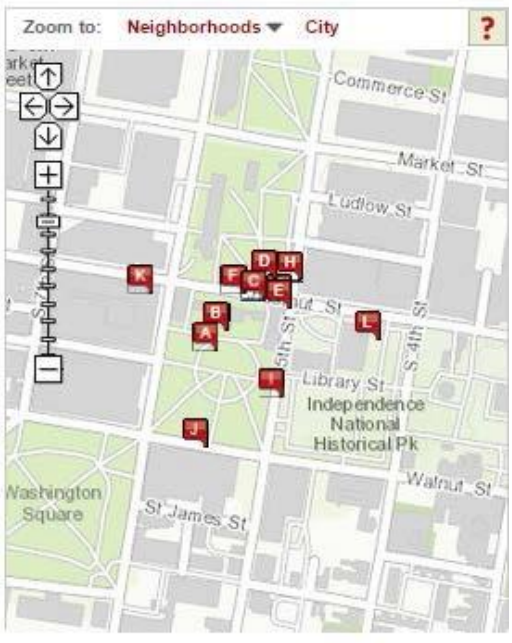

Figure 7: Google map of downtown Philadelphia.

collection in Google Earth. Currently, there are almost 110,000 images making this a rather dense set of imagery, but as you zoom in the image number decreases (Cheetham, 2007). Google Earth allows the user to glide over a 3D version of Philadelphia, click on historic images and view them in Google Earth Street View (see Figure 5) which brings you down to the street level to see how it looks today. Google Street View provides the user with current street level photographs of Philadelphia allowing them to see landmarks, streets, and neighborhoods without having to travel to the city. PhillyHistory.org offers their users the chance to see how a historic image they are viewing looks today by linking the historic image with the current Google Street View image (see Figure 6). Google Maps allows users to visually see the neighborhood and location of the image (see Figure 7) and choose images based on location. 
PhillyHistory.org also offers new crowdsourcing possibilities to engage the public by allowing them to add comments, register as a user, add images to favorites or email staff error reports. Also viewable are social media links to Twitter, Facebook, Pinterest, Google Plus and a blog to allow users to share and exchange photographs, information, ideas, and stories. Patrons can also submit a scan request that is added to the queue (ESRI, 2005, p. 13). This form of crowdsourcing engages the public with the program, gains their feedback on the site, and increases public use while simultaneously helping staff to prioritize scanning based on public demand.

Two major revenue-generating options available from this page are purchase and license capabilities. Patrons interested in purchasing a professional print are able to choose the size, type of paper, and style of the print requested. Other options include purchasing images on posters, canvas or greeting cards, invitations or postcards. The card option allows the purchaser to add a customized personal message. This is all done through a third party company. In order to license images, you must be a registered user and approve the scope of an agreement limiting use.

In 2008, PhillyHistory.org began working collaboratively with the Philadelphia Free Library, Library Company of Philadelphia, the Office of the City Representative, and the Philadelphia Water Department to serve as their online repository. This not only created one site for a significant amount of Philadelphia's historic photographs but also streamlined assets, staff allocation, subject matter expertise, and resources. In addition, each organization or department receives any net revenue from the sales of their images while maintaining all licensing and copyright (Boyer, et al., 2011, p. 659). This collaboration effort allows smaller organizations and departments to earn extra 


\section{Table 1}

PhillyHistory.org metadata options for Topic, Series, Collection, and Advanced Search Options available via drop down lists.

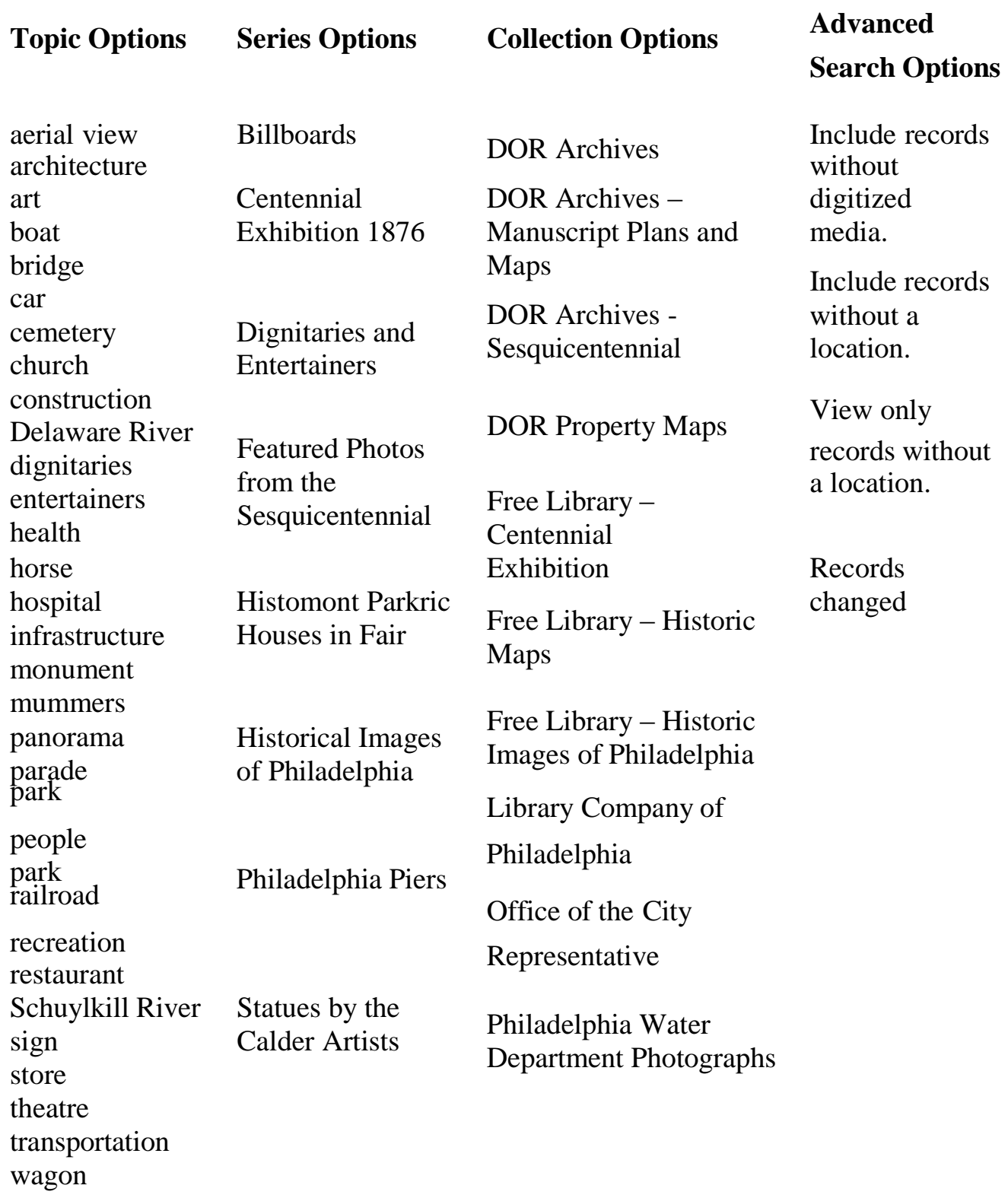




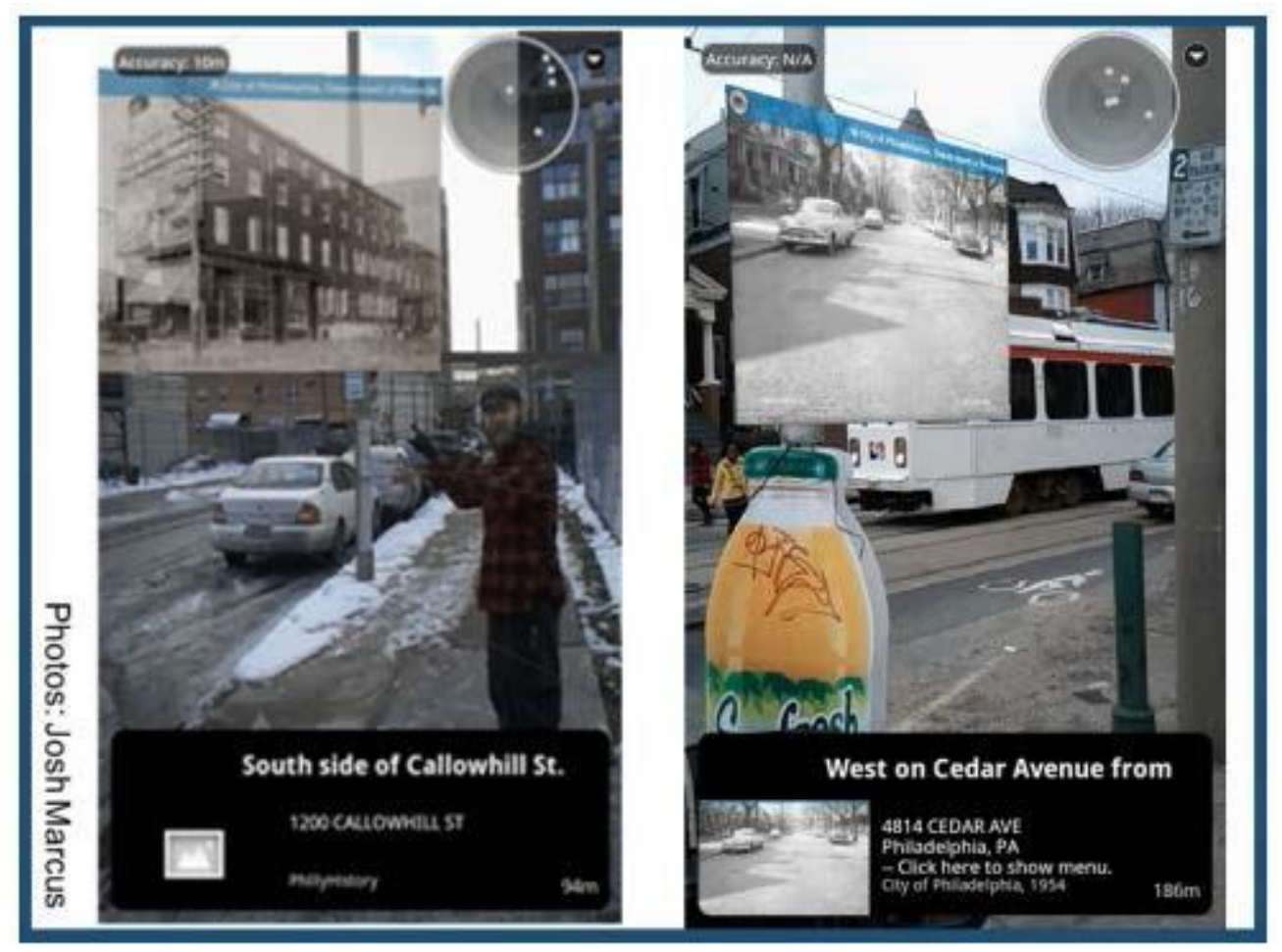

Figure 9: Augmented Reality app optimized for smart phones provides the user with geographic search access to the entire collection. The image on the left shows the photograph in relative position where it faces the user. The image on the right shows the photograph at an angled view based on coordinates (Azavea, 2011).

revenue for their programs, reap visibility benefits, demonstrate value to stakeholders and the community, and increase user access to their collections.

PhillyHistory.org metadata has been derived from the original storage envelope each image or negative is stored in. Interns add as much descriptive metadata as available while a team of researchers investigate the location to more accurately describe and geocode each image (Boyer, et al., 2011, p. 657). The descriptive metadata, which appears to use Dublin Core elements, includes title, description, quotation, notes, address, date, collection, collection ID, asset ID, topics, series, and any hyperlinks to related materials or websites (see Figure 8). The topic, series, collection and advanced search options provide drop down lists allowing patrons to refine their search parameters (see Table 1). The patron can use any of the search options alone, combine two or more for the same data 

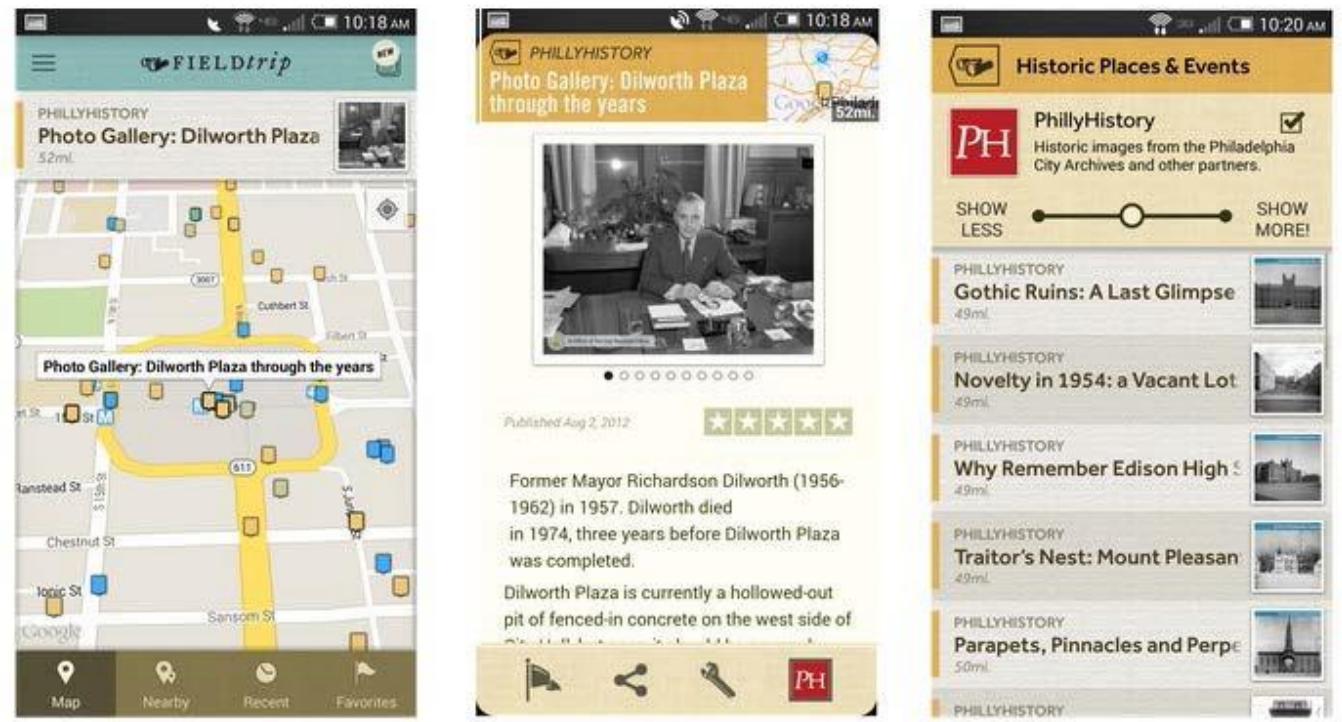

Figure 10: PhillyHistory.org returns for Dillworth Plaza (The PhillyHistory Blog, 2014)

source, use them in combination with a search box at the top of the screen or set date parameters.

In 2007, DOR launched its new addition PhillyHistory.org Mobile app, to increase collection access via cell phone, tablets, and other mobile devices. This new technology, optimized for Apple and Android devices, allows users to view images while at any location which creates a unique "walking tour" through history as they explore the city and its rich history.

The Department of Records was awarded an NEH Digital Humanities StartUp Grant in 2010 to develop innovative techniques for merging historic and modern photographs on smartphones which would expand public access to historic data and create a challenging and dynamic user experience. The result was Augmented Reality, a new software program designed to augment people's experience with the world by overlaying it with additional digital information and assets. The application provides point-and-view access which allows users to access and view historic photographs of selected sites (see Figure 9). The user points the smartphone camera at the contemporary site and selects one of the available photographs (Azavea, 2011). The historic photograph then appears as an overlay on the current view via the camera, enabling users to view the location as it was in the past.

In an effort to increase access and enhance the user experience, PhillyHistory.org worked in conjunction with NianticLabs@Google, creators of 
Field Trip, to provide a cultural guide to the city's hidden history (The PhillyHistory Blog, 2014). Field Trip is a guide to the world around you and available free on both iPhones and Android devices. The app runs on your phone in the background and tells you when you get close to something interesting available on their site (Field Trip, 2015). It not only shows you images but also gives you the geographic location and historic details and can even read the information to you. Field Trip allows users to explore locations around the world including historic places and events, architecture, museums, art, and public history (see Figure 10).

PhillyHistory.org chose selected materials from their collection to be available through the Field Trip app as a way to increase collaborative efforts and visibility. As the user traverses the city streets, historic images emerge allowing the user to experience an enhanced and dynamic view of Philadelphia's history not previously experienced (The PhillyHistory Blog, 2014). This new altered interpretation provides users with a unique geographic and cultural experience while going about their day-to-day tasks or while exploring the city.

\section{Conclusions}

PhillyHistory.org has created a new dynamic way to merge special collections with GIS technology to gain intellectual and physical control of their collection; increase user access; collaborate with local and community organizations; and create a challenging, thought-provoking site. The institution showed how geography can be utilized to engage the public, create enthusiasm for historic collections, help obtain resources and support, and enhance the user experience. PhillyHistory.org has been so successful that they have not only garnered media and public attention but also special collection organizations have taken note and are using similar software, applications, and techniques to create new challenging geospatial-based digital access to their collections.

Twenty-first century collection managers are constantly seeking progressive solutions and technology to digitize their assets and make them available online. This ability to preserve their collections while reaching a global audience has become paramount to institutions that, like DOR, have materials deteriorating in the stacks, unknown and undiscovered by patrons. In order to reach these patrons, they must utilize current technology. Using GIS technology is one way to challenge patrons and increase access and interest in their collections.

Future research in this area should explore the different ways geospatialbased applications can be merged with special collections, museum artifacts, and oral histories to engage and challenge users. The advent of new and burgeoning GIS technology, social media, and interactive applications allows institutions to explore the multitude of ways collections can be used to increase access and 
enhance the user experience with cutting edge technology. Projects using geospatial-based applications and GIS technology are still in their first decade of use and collection managers are just beginning to explore the many innovative possibilities available. Institutions must continually explore the existing opportunities to transform their collections into dynamic, interactive mashups with progressive interface capabilities. The possibilities are limitless as institutions are only hindered by the imagination of staff, patrons, and the global communities they serve.

\section{References}

Azavea. (2011). The Philadelphia Department of Records and Azavea release white paper on augmented reality technology research along with AR App for historical photos. [Press release]. Retrieved from http://bit.ly/1PGG2G8

Bentham, B. (2011, February 2). 2010: The year of crowdsourcing transcription. [Web log article]. Retrieved from http://bit.ly/1NjtIeQ

Boyer, D., Cheetham, R., and Johnson, M.L. (2011). Using GIS to manage Philadelphia's archival photographs. American Archivist 74(2), pp. 652-663.

CENDARI. (2015). About CENDARI. Retrieved from http://bit.ly/1I3JxUF

Cheetham, R. (2007). "Googling” Sajara: how Sajara uses Google Earth and Google Maps...O'Reilly Radar calls it "fantastic." Azavea Journal 2(6). Retrieved from http://bit.ly/1SbLv5M

City of Philadelphia Department of Records \& Azavea. (2011). Augmented reality by PhillyHistory.org. [White paper]. Retrieved from http://www.azavea.com/index.php/download_file/view/655/

Cornwell, B. (2015, January 6). Making and breaking UX best practices. Retrieved from http://bit.ly/1xOwRbA

Day, J. (2011). The New York Public Library uses crowdsourcing to update its archives. Retrieved from http://bit.ly/21aNoFX

Engard, N. C. (2009). Library mashups: Exploring new ways to deliver library data. Medford, NJ: Information Today, Inc. 
Engard, N. C. (2015). More library mashups: Exploring new ways to deliver library data. Medford, NJ: Information Today, Inc.

Erway, R. \& Schaffner, J (2007). Shifting gears: gearing up to get into the flow. OCLC Programs and Research. Retrieved from http://bit.ly/1Njtq7N

ESRI. (2005, Fall). Citizens can access mapped historic photos. Government Matters. Retrieved from http://bit.ly/1N0GAA4

Geo Community. (n.d). General GIS information. Retrieved from http://data.geocomm.com/helpdesk/general.html

Gueguen, G. \& Hanlon, A.M. (2009). A collaborative workflow for the digitization of unique materials. Journal of Academic Librarianship, 35(5), 468-474. doi:10.1016

Howlett, S., Machin, J., \& Malmersjo, G. (2005). Volunteering in museums, libraries, and archives. Institute for Volunteering Research. Retrieved from http://www.volunteerspirit.org/files/volunteer_survey_2006_9500.pdf

Hunter, N.C., Legg, K., \& Oehlerts, B. (2010). Two Librarians, an archivist and 13,000 images: collaborating to build a digital collection. Library Quarterly 80(5), 81-103.

Kelley, M. (2011). Collaborative digital techniques and urban neighborhood revitalization. National Association of Social Workers 56(2), 185-188.

Madrigal, A.C. (2012, December 13). Why Google Maps is better than Apple Maps: there's a simple answer: people. The Atlantic. Retrieved from http://theatln.tc/1YmPoZk

Miller G. (2014, December 8). The huge, unseen operation behind the accuracy of Google Maps. Wired. Retrieved from http://bit.ly/1vwAsqh

Nagasaki Archive. (2015). Concept. Retrieved from http://bit.ly/1MJvO1W

Old Weather. (2015). Old Weather: our weather's past, the climate's future. Retrieved from http://www.oldweather.org/

Philadelphia thanks GIS for the memories. (2008, fall). ArcNews Online Retrieved from http://arcg.is/1kOhTRl 
Phillyhistory.org. (2015). Retrieved from http://bit.ly/1KiqyAr

Riley, J. \& Shepard, K. (2009). A brave new world: archivists and shareable descriptive metadata. American Archivist 72(1), 91-112. Retrieved from http://www.jstor.org.libaccess.sjlibrary.org/stable/40294597

San Fernando History Digital Library. (2015). About this collection. Retrieved from http://digital-library.csun.edu/cdm/landingpage/collection/SFVH

Schmidt, A. \& Etches, A. (2014). User, usable, and desirable. Chicago: ALA Editions.

Schmidt, A., \& Etches, A. (2012). User experience (UX) design for libraries: (THE TECH SET ${ }^{\circledR}$ \#18). Chicago: ALA Editions.

Science Education Resource Center (SERC). (2015). What is Google Earth? Retrieved from http://serc.carleton.edu/29016

Simon, N. (2010). The participatory museum. Santa Cruz, CA: Museum 2.0.

Stanford. (n.d.). Bassi-Versatti Collection. Retrieved from http://stanford.io/1IJJEiW

Story Maps. (2015). Retrieved from http://storymaps.arcgis.com/en/

Strickland, J. (n.d.). 10 useful Google Tools. How Stuff Works. Retrieved from http://computer.howstuffworks.com/internet/basics/google-tool6.htm

The PhillyHistory Blog. (2014, May 16). PhillyHistory now available on Field Trip [Web log]. Retrieved from http://bit.ly/1MJuTPa

Wolfe, J. (2011, May 5). Libraries commemorates Civil War sesquicentennial with exhibition, digital collection, crowdsourcing effort. Crowdsourcing.org. Retrieved from http://bit.ly/1OYZeiw 